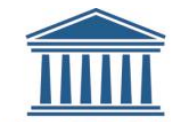 \\ UNIVERSITEIT \\ GENT
}

\section{biblio.ugent.be}

The UGent Institutional Repository is the electronic archiving and dissemination platform for all UGent research publications. Ghent University has implemented a mandate stipulating that all academic publications of UGent researchers should be deposited and archived in this repository. Except for items where current copyright restrictions apply, these papers are available in Open Access.

This item is the archived peer-reviewed author-version of:

Title The syntax of registers: Diary subject omission and the privilege of the root

\author{
Authors Liliane Haegeman \\ In: $\quad$ Lingua, 130, 88-110. \\ http://dx.doi.org/10.1016/j.lingua.2013.01.005
}

To refer to or to cite this work, please use the citation to the published version:

Haegeman, Liliane. (2013) The syntax of registers: diary subject omission and the privilege of the root. Lingua 130: 88-110. 


\title{
The syntax of registers: Diary subject omission and the privilege of the root
}

\author{
Liliane Haegeman \\ Department of Linguistics \\ Ghent University/GIST ${ }^{1}$
}

\section{Introduction: Register based variation}

It has frequently been observed that a pattern that is judged ill-formed in a language may become acceptable in specific registers of usage of the same language (Ferguson 1982, Zwicky and Zwicky 1982, Biber 1995, Barton 1998). In English, even when contextually recoverable, subjects of finite clauses (1) and objects in general (2) cannot be omitted, and singular countable nouns have to be accompanied by a determiner element (3), such as an article or a possessive pronoun.

(1) a. This dish serves four people.

b. *_Serves four people.

(2) a. You should bake the chicken for an hour.

b. * * You should bake __ for an hour.

(3) a. A man ordered his wife to shoot her sister.

b. *_ man ordered __ wife to shoot__ sister.

Examples similar to those in (1b), (2b) and (3b) are attested in specific registers. Subject omission is one of the hallmarks of diary writing, as illustrated in the attested (4), object omission is typically found in instructional type writing such as recipes (5), newspaper headlines display singular count nouns without determiner (6):

(4) Origo rather contorted: __ says Italy is blind red hot devoted patriotic; __ has thrown her wedding ring into the cauldron too. ___ Anticipates a long war... (Diary of Virginia Woolf, V: p. 6, 10 January 1936)(cf. Haegeman, 1990a, 1990b, 1997, 1999).

(5) Put the prepared potato chunks into a large saucepan with enough salted water to take the pasta later, and bring __ to the boil.

(http://www.bbc.co.uk/food/recipes/pasta_alla_genovese_with_63248)

(6) wife to shoot sister. (Stowell 1997: his (4)) 
As a general property, the patterns displayed above all involve a form of ellipsis, i.e. the nonexpressing of certain content, and one might propose a 'functional' deletion rule along the lines of (7) (based on Stowell 1997):

Delete any constituent whose meaning is recoverable, either from the context or from the grammar.

However, while recoverability does indeed play its part, it is not the sole determining factor. In the diary register, a first person subject is recoverable par excellence, since diaries are by definition about their writers. And yet, in (8) the underlined first person subject pronouns cannot be omitted . In (8b) recoverability can hardly be an issue: the presence of the reflexive myself eliminates any ambiguity as to the interpretation of the subject of $d o$. Similarly in (8c), it is contextually clear that the subject of the relative where clause is the diary writer (cf. for early discussion: Haegeman (1990, 1997). While plausibly the first overt pronoun he in (8e) might not be fully recoverable, the second occurrence is fully recoverable and yet it cannot be omitted. These contrast will be dealt with in section 3.2.

(8) a. _ Dreamt that $\underline{I}$ picked up a New Yorker. (Plath 304)

b. __ Read my annual message. It was good if $\underline{I}$ do say it myself. (Truman diaries: http://www.trumanlibrary.org/diary/page3.htm, 7 January 1947.)

c. __ Never saw such crowds-such enthusiasm. __ Arrive at Embassy [,] _ _ bid President goodbye. __ Have dinner at Palace where I make a speech in reply to the [Truman writes "Tuesday night" above this part of the entry] Mexican President. (Truman diaries: http://www.trumanlibrary.org/ diary/page3.htm, 7 January 1947.)

d. Before I went, Clive came to tea. (Virgina Woolf Diary, III: 26 December 1929)

e. __ Says he has been struck by the number of more or less ordinary Conservatives he has met who are becoming perturbed by the Government's foreign policy. (Orwell diaries, Villa simontS, 22.11.38, http://orwelldiaries.wordpress.com/2008/11/

Similarly, object omission in recipe contexts is not free. In (9a), though contextually recoverable, the object pronoun it cannot be omitted. Crosslinguistically, the descriptive generalization seems to be that object omission in instructional writing is restricted to clauses lacking an overt subject such as imperatives or non-finite clauses (see Massam (1989), Massam and Roberge (1989, Maling and Sigurdsson 2007 for much relevant discussion). 
(9) Remove the saucepan from the heat before you drain *(it) of pasta and potatoes. (based on http://www.bbc.co.uk/food/recipes/pasta_alla_genovese_with_63248)

Stowell (1996) highlights that recoverability is not the only factor that determines omission of determiners in headlinese (6). In (6) for instance, the determiner associated with sister is not fully recoverable: is it 'his' sister or 'her' sister? (10) - from Stowell 1997:2, his (8) - shows that, in addition to total deletion of all determiners, partial deletion of some determiners in a headline may be licit (10b), but this is by no means freely available (10c). Stowell (1997) discusses a number of syntactic constraints governing determiner omission in headlinese. I refer to his paper for discussion.

(10) a. Beverly hills housewife finds rare gold coin.

b. A Beverly hills housewife finds rare gold coin.

c. Beverly hills housewife finds a rare gold coin.

We conclude that, though recoverability no doubt plays a role, register specific omission phenomena cannot purely be analysed in functional terms and that they are subject to syntactic constraints. In the present article I focus on diary subject omission, abbreviated henceforth as DSO. It is obviously not desirable that an account of DSO should have to invoke a ream of novel principles geared specifically to the phenomenon of DSO. If DSO is also grammar-based (rather than being purely functional), it should follow from grammatical principles which have been independently deployed to account for linguistic phenomena in English or in other languages. In addition, it has been shown in the literature (cf. Haegeman 1997 for a survey) that DSO patterns very much like subject omission in child language. Hence, it is be desirable for the two manifestations of subject omission to be made to follow from similar, or even identical, mechanisms. After evaluating a number of existing analyses I will develop an analysis of DSO based on Rizzi's (2006) analysis of null subjects in early child production, using the cartographic model of formal syntax (Cinque and Rizzi 2010) and insights from Phase theory (Chomsky 2001).

The paper is organized as follows : Section 2 discusses the variation between languages that allow subject omission in finite clauses and those that don't, section 3 evaluates three analyses of DSO. Section 4 briefly presents the main ingredients of Rizzi's (2006) analysis of subject omission in the production of young children and introduces the idea that finite clauses do not have a unique subject position. Section 5 explores an analysis DSO data that capitalizes on Rizzi's analysis of early subject omission coupled with insights about subject positions from the cartographic approach. In section 6 it is shown that the 
restrictions on subject omission observed in the paper are also found in other contexts. Section 7 is a brief summary.

\section{Cross linguistic variation}

\subsection{The Pro drop parameter}

Languages differ with respect to the extent to which a contextually recoverable subject of a finite clause is realised as a pronoun. In so-called pro drop languages such as Italian, a subject pronoun can remain unexpressed in a finite clause while in English and in French, for instance, this is not possible. (Jaeggli \& Safir 1986, Rizzi 1986).
(11) a. Parla inglese.
(Italian)
b. *Speaks English.
c. *Parle anglais. (French)

Though lacking an overt subject such as lui ('he'), lei ('she'), Italian (11a) is understood as if it contained a subject. This can readily be demonstrated by means of examples such as (11d) in which a reflexive pronoun, se stesso ('himself'), takes as its antecedent the understood subject of parla:
(11) d. Parla sempre di se stesso.
(Italian)
speak-PRES-3SG always of himself
'He always speaks about himself.'

As a rule, reflexives are referentially dependent on an antecedent: (11e) is unacceptable because the reflexive se stesso ('himself') lacks an antecedent: the only potential antecedent is Maria a feminine singular nominal expression which does not match the masculine singular reflexive se stesso.
(11) e. *Maria parla sembre di se stesso. (Italian)
Maria speak-PRES-3SG always of himself

Yet, while the reflexive se stesso in (11d) lacks an overt antecedent, the sentence is acceptable. One way to account for this is to say that the subject of (11d) is a non-overt pronoun ( pro) and that such pronouns are licit in Italian but not in English or French. The cross linguistic variation observed here has been 
related to differences in the verbal agreement paradigms. The agreement paradigm of the Italian verb is 'rich': the finite inflection has a distinct form for each person/number combination (parlo, parli, parla, parliamo, parlate, parlano, 'speak', present tense paradigm). There are different ways of formalizing a causal link between agreement and subject omission. One might say, for instance, that the agreement inflection of the Italian finite verb has nominal properties and functions as a subject (see Alexiadou \& Anagnostopolou (1998)) or one might say that a pronominal subject can be deleted provided the agreement inflection on the finite verb reduplicates all its grammatical features. (For discussion of the relation between inflection and the pro drop phenomenon see Rizzi (1982), Jaeggli \& Safir (1986), Alexiadou \& Anagnostopolou (1998)).

There are a number of other contrasts with respect to the subjects of finite clauses in Italian and English (Rizz 1982). Italian weather verbs such as rain do not take an overt (expletive) subject, while English weather verbs must have an expletive subject, it (12). A definite lexical subject may follow the verb in Italian, an option unavailable in English (13). Questioning the subject of a subordinate clause in Italian (14a) is compatible with the presence of the subordinating conjunction che ('that'), while the English analogue in (14b) is unacceptable. (14b) is rendered acceptable by omitting the conjunction that.

(12) a. (*Esso) piove.

(*it) rain-PRES-3SG

b. $\quad *($ It $)$ is raining.
a. L 'ha detto Gianni.
It have-3SG say-PART Gianni

b. *Has said it John.
a. Chi credi
che abbia
telefonato?
who think-PRES-2SG that have-SUBJ-3SG telephoned
b. Who do you believe (*that) has phoned?

\subsection{Register variation}

Though I will mainly concentrate on English DSO is also found in French diary styles and in note style writing, as shown in (15). I will occasionally point out relevant facts from French.

(15) a.

$\begin{array}{ll}\text { L M'accompagne } & \text { au Mercure, } \\ \text { me accompany-3SG } & \text { to-the Mercure, } \\ \text { Revient à l'affaire Alb... }\end{array}$
Me demande si... 
Return-3SG to the business Alb. Me ask-3SG if...

(Léautaud, P. Le Fléau, Journal particulier. 1917-1930, pp. 69-70, 20.3)

b. Préparons les photocopies.

Prepare-1PL the photocopy-PL (attested example, email message)

It is often thought that subject omission in diaries is restricted to first person subjects. That this generalization is incorrect is shown by (4) for English and (15) for French. In her study of a 30 page excerpt from the Virginia Woolf diaries (V: 1940), Tabea Ihsane reports that 111 referential subjects are omitted, of which 53 first person singular, 17 first person plural, 36 third person singular, and 5 third person plural. Observe that first person singular omissions do not even represent 50 percent of all cases, contrary to common belief (Ihsane 1998: 24, table F). It is true, though, that while first person subject omission is the default case and can arise 'out of the blue', third person subjects can only be omitted provided a referent is made contextually salient.

Though lacking an overt subject, the examples with DSO will be interpreted as having a subject. (16a) is an attested example with a reflexive myself referentially dependent on the implicit subject, (16b) is a French example of the same type. In (16c) the participle attendue ('expected') is feminine singular and agrees with the implicit subject 'she'. Though implicit, the subjects in such diary style sentences is syntactically represented, i.e. it is syntactically active entity with the grammatical properties of a subject but which is not spelt out.

(16) a. Sept. 2d. Have busied myself to-day in unpacking my trunk and arranging my things for a visit to Vancouver. (1836) http://www.isu.edu/ trinmich/00.ar.whitman1.html

b. _ _ s'est donné souvent l'illusion de l'amour à P. REFL. Be-3SG give-PART often the illusion of the love to $\mathrm{P}$ (Léautaud 1924, 1 March)

c. Jamais __ne se serait_attendue à cela never ___ ne herself be-COND-3SG wait-PART-FEMSG to this

(Léautaud: 1933: 96)

The question arises exactly what differentiates the register allowing implicit subjects from the core register, which disallows them. I first evaluate a number of $a$ priori attractive analyses. The discussion will allow me to bring up the salient grammatical properties of the implicit diary subjects. 


\section{Three analyses}

\subsection{Against the fragment analysis}

Starting from the assumption that languages are structured according to a universal template, I assume that the blueprint for the formation of the syntactic constituent is the format (17a):

a.

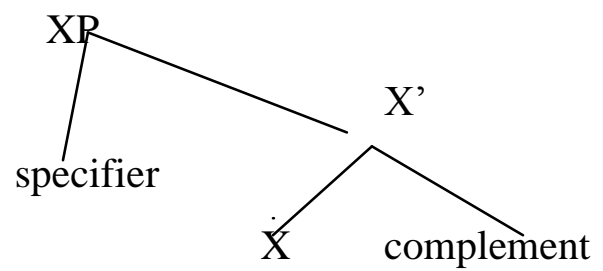

Constituents are built around a head (X, in (17a)), they combine with a complement, and the resulting unit (labelled X') is combined with a 'specifier'. Noun phrases (NP) are built around a head Noun, Verb phrases (VP) around a Verb, etc. Sentences consist of three structural layers, each in accordance with (17a): (i) VP, (ii) the Tense Phrase (TP, also labelled IP) and (iii) the layer of the complementizer- CP:

b.

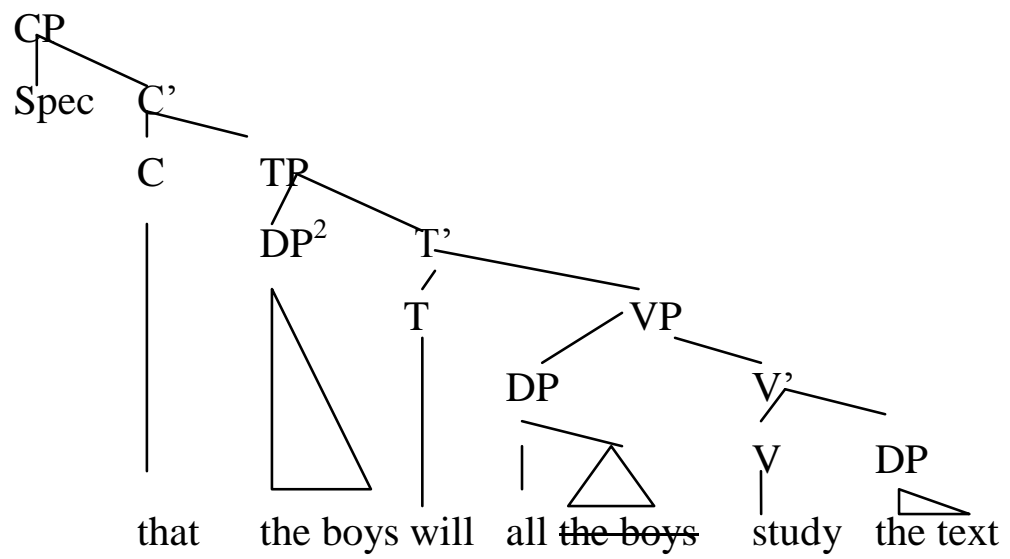

TP is built around the temporal, modal and aspectual properties of the verb; $\mathrm{CP}$ is headed by the position $\mathrm{C}$, which hosts the conjunction. Each layer of the clause is associated with a specialised semantics: VP encodes the core properties of the action/state expressed in the sentence ('who does what to whom', including the participants in the action (AGENT, PATIENT, BENEFICIARY etc)); TP encodes the localisation of the action/state expressed in the VP with respect to temporal, modal and aspectual properties; $\mathrm{CP}$ encodes relations between the sentence and the discourse. It is further proposed that the subject (here the boys) originates VP internally and moves to the TP layer; this is indicated by strikethrough. The quantifier all in (17b) is stranded in the base position of the subject. 
$\mathrm{CP}$ encodes properties related to information structure or illocutionary force. For instance, English root constituent questions are derived by the leftward movement of an interrogative constituent to the specifier of $\mathrm{CP}$, accompanied by movement of the finite auxiliary from $\mathrm{T}$ to $\mathrm{C}$. The moved constituent which text specifies the scope of the question:

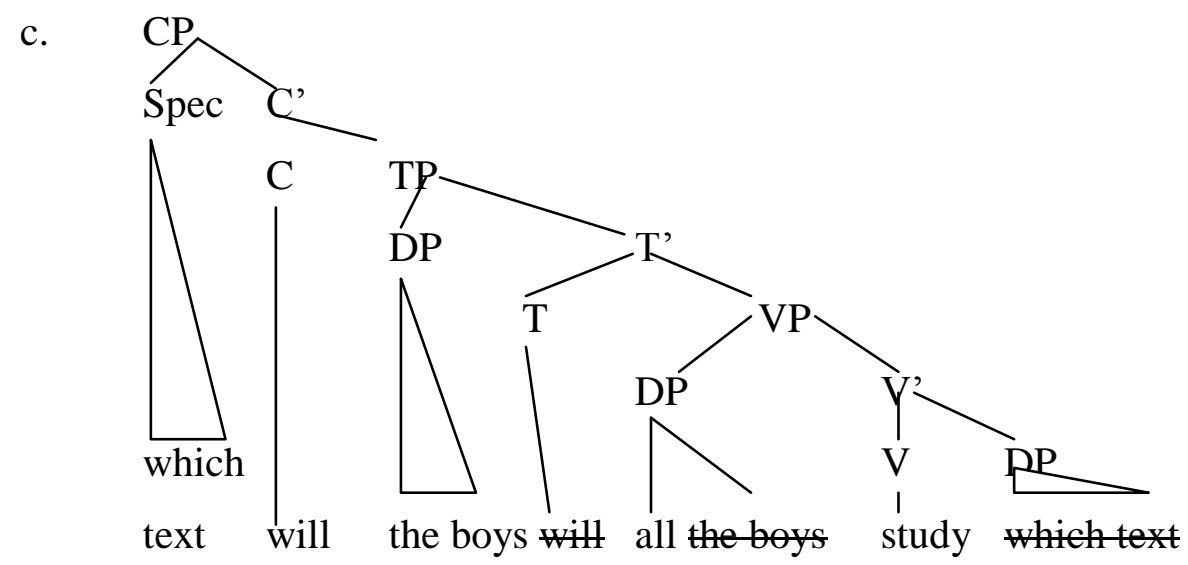

As a first hypothesis one might propose that DSO patterns are actually found in sentence fragments, possibly in untensed VPs which are not projected to the higher levels. (cf. Progovac et al (2006), who relate the availability of non-sentential fragments to tenselessness). However this cannot be correct for all examples of DSO: empirical support for a clausal analysis is the observation that DSO is compatible with the presence of finite auxiliaries, which are standardly taken to belong to the TP layer. See 5.2.2. for arguments that finite auxiliaries are in $\mathrm{T}$.

(18) a. ㄴ Have done 110 pages. (Virginia Woolf, V: p. 33)

b. __ Am reading the book of Job. (Plath, 1959: 290)

c. _ May drive to Paris with him. (Plath 1959: 127)

\subsection{Positive setting of the pro-drop parameter?}

A second hypothesis might be that DSO patterns arise as a result of a parametric resetting in the specific register under discussion. One might think that unlike is the case in the grammar of English, the diary variety makes available the pro drop option, an option independently available in, say Italian or Spanish.

Though initially attractive, equating subject omission in the early production and $\mathrm{DSO}^{3}$ with the subject omission in pro drop languages would raise a host of problems.

(i) Whereas in pro-drop languages such as Italian the person and number inflection of the finite verb parla 
('speak') allows identification of the implicit subject (11), English verb inflection does not always suffice to identify the subject in DSO patterns. While some attested instances may allow for full feature recovery $(19 \mathrm{a}, \mathrm{b})$; in other cases the only restriction imposed by the inflection of the verb is that the subject not be a third person singular $(19 \mathrm{c}, \mathrm{d})$, and in many instances the inflection offers no indication at all as to the nature of the implicit subject (19e,f).

(19) a. Am reading the book of Job. (Plath, 1959: 290)

b. Has thrown her wedding ring into the cauldron too.

c. Have been awake since black 3.30. (Plath, 1956, 154).

d. _ Write down the passing thought. (Plath, 1956, 165)

e. Couldn't even read. (Plath, 1956, 108)

f . _ _ Got up as brash, nerve-raking alarm ground off at 6. (Plath, 1956, 54)

Moreover, while the implicit subject in pro-drop languages is available in embedded clauses (20), DSO is restricted to main clauses: in particular, it is incompatible with declarative complement clauses (8a,e) regardless of the presence of that, with interrogative complement clauses $(8 \mathrm{~b})$, with relative clauses $(8 \mathrm{c}, \mathrm{e})$ and with adverbial clauses $(8 \mathrm{~d}) .^{4}$

(20) I ragazzi cantano [quando lavorano.] (Italian) The boys sing-3PL when work -3PL

(iii) While the null subject in pro-drop languages is allowed in root questions, as shown in Italian (21), the English DSO does not occur in this context, as shown by (22). This observation was made for spoken English by Napoli (1982), Schmerling (1973) and Thrasher (1977), and was shown to extend to the diary style in Haegeman (1990, 1997):

(21) (Quando) tornerà ?

(when) return-FUT-3SG?

'(When) will he/she return?'

(22) a. * $(\underline{\text { When }}) \underline{\text { will }}$ see her again?

b. * A Are _ coming to dinner tonight?

(iv) In pro-drop languages subject omission is compatible with the initial position of an argument of the 
verb (23); the same context is incompatible with DSO (20) (Thrasher 1977: 83; Haegeman 1990, 1997):

(23) Questo libro, __ non lo voglio.

this book non it want-1SG

(24) *This book, __ didn't like. (Wilder 1995: 36-7) ${ }^{5}$

From the discussion so far one might conclude that in order to be omitted the subject must be on the leftmost edge of the clause. This generalisation is probably correct for spoken English (Napoli 1982, Weir 2009), though there may be inter speaker variation given that Thrasher (1997: 80) accepts (24). However, while in the written register argument fronting is unattested (and judged unacceptable by informants) with DSO, initial circumstantial adjuncts are allowed as shown by (26) (cf. Haegeman 1997, 1999)

(25) Next time you get to Kobe, want you to buy me an umbrella (Thrasher 1977: 80)

(26) a. With a sigh of relief saw a heap of ruins. (Woolf V: 1940, 330; Ihsane 1998, (40j))

b. After Dr. Krook, __ had good lunch at Eagle with Gary [Hamp]. (Plath 126)

c. $\quad$ Here, __ studies under [David] Daiches...(Plath 126)

d. This morning _ _ woke to get a letter in the mail from the estimable Dudley Fitts. (Plath 304)

The adjunct/argument asymmetry also characterizes French DSO: (27a) is not attested and judged unacceptable. Examples with initial adjuncts are attested (16c) and (27b-e). ${ }^{6}$

(27) a. *Son frère, __ l'accompagne au bistro.

her brother, __ _ him accompanies to the pub

b. puis __se colle à moi et me tend sa bouche._ (Léautaud: 1933: 31) then ___ cling-3SG to me and me presents her mouth

c. De nouveau __ me tend sa bouche (Léautaud: 1933: 31) again __ me present-3SG her mouth

d. Tout de suite __ m'a parlé de ma visite chez elle dimanche (Léautaud: 1933:45) immediately ___ me have-3SG talk-PART about my visite to her Sunday

e. Après bien de conversation, étendue sur son divan, __ me demande de venir près d'elle 
(Léautaud: 1933: 50)

after some conversation, stretched out on her sofa ___me asks to come to her

Needless to say, the other properties that distinguish subjects in pro-drop languages from that in English remain absent from the English or French diary register.

\subsection{Subject omission as topic drop}

\subsubsection{Topic drop: the phenomenon}

In some languages, a sentence topic may remain non-overt. For instance, in European Portuguese (Raposo 1986) (28), the object of the verb, guardou ('keeps'), is non-overt. Argument ellipsis may affect an argument in the main clause (28a) or in the embedded clause (28b):

a. O Manel guardou no cofre da sala de jantar. (Raposo 1986: 381, his (16a)) Manuel kept _ in the safe of the dining room

b. Eu disse ao António [que pedise ao Manel [que gardase no cofre de sala de jantar]]. (R 1986: 381: (16b))

I told Antonio that he asked Manuel to keep in the safe of the dining room

Raposo (1986) develops a movement analysis to account for the properties this implicit topic. Simplifying somewhat, the idea is that the topic is moved to the $\mathrm{CP}$ of the matrix clause, where it is allowed to be nonovert. The movement analysis accounts for the island effects iin (29): in these examples the implicit object would have to be extracted from within the clausal complement of a noun; in (29b) the object would be extracted from inside an adjunct, in (29c) the object would be extracted from within an embedded interrogative. These three domains are islands: they are independently known to resist extraction (see Raposo 1986 for discussion).

(29) a. *Eu informei a polícia da [possibilidade [de o Manel ter guardado no cofre de sale de jantar]]. (Raposo 1986: 381: (16c))

I informed the police of the possibility that Manuel had kept in the safe of the dining room

b. *O pirata partíu para as Caraíbas [depoís de ter guardado cuidadosamente no cofre]. (Raposo 1986: 382: (19)

The pirate left for the Caribbian after he had kept __ carefully in the safe

c. *Eu sei [[em que cofre] o Manel guardou ___ ] (WH island) (Raposo 1986: 383: (20)) 
I know in which safe Manuel kept

A movement analysis for non-overt topics also accounts for the constraints on topic drop observed in German and Dutch, and in particular for the fact that such non-overt topics must occupy the first position (30). Given that these are V2 languages with the finite verb in second position, a fronted topic will immediately precede the finite verb and sentences with a non-overt topic will be superficially verb-initial. ${ }^{7}$ In German (30a), the topic das ('that') is fronted. In (30b), the fronted topic is non-overt. As predicted, only initial topics can be non overt (30c). The same pattern obtains in Dutch. The German and Dutch data thus corroborate Raposo's movement analysis: a topical argument may be non-overt if moved to the left edge of the clause. As shown by (30d-f), subject topics may also be non-overt, provided they too occupy the initial position:
a. Das habe ich schon gesehen.
(German)
that have I already seen
'I have already seen that/it.'
b. $\varnothing$ Habe ich schon gesehen.
c. $\quad *$ Ich habe $\varnothing$ schon gesehen.
d. Ich habe das schon gesehen.
I have that already seen.
'I have already seen that.'
e. $\varnothing$ Habe das schon gesehen.
f. $\quad *$ Das habe $\varnothing$ schon gesehen.

We predict that expletive subjects, which are non-referential and thus cannot be informational 'topics', should not be subject to topic drop. Portuguese being a pro-drop language this cannot be tested, since expletive subjects will be null pronouns (cf. (12)), but the prediction is correct for German and Dutch in which impersonal subjects in initial position cannot be non-overt.
a. $\quad *($ Es $)$ wurde viel getanzt.
(It) was a lot danced
b. $\quad *($ Es) hat viel geregnet.

(German)

(It) has a lot rained

Recently Sato (2011) provides interesting support for the movement analysis of null topics from 
Japanese. In this language, topicalised arguments are accompanied by the marker $w a$ which Whitman (1997) analyses as a clausal functional head. Sato (2011: 1, (1)) provides patterns such as those in (32) in which the topical nominal associated with $w a$ is omitted. The data are from Nasu (2010), his (1). (32b) can be analysed as (32c), with a non-overt topic: the non-overt nominal associated with wa moves from the specifier of FP to the specifier of TopP in the left periphery of the clause.
a. Keetai-wa
Sony -no
kisyu-ga
hayattemasu.
(overt topic) mobile-TOP Sony-GEN
machine-Nom popular
'Speaking of mobiles, Sony's machines are popular.'
b $\quad \varnothing$-wa Sony-no kisyu-ga hayattemasu.
$\varnothing$-TOP Sony-GEN machine-NOM popular
c $\quad[$ topp Keetai $[\mathrm{Top}] \quad[$ FP Keetai [F Wa] ...

\subsubsection{Diary subject omission as topic drop?}

It is tempting to equate DSO with topic drop, as proposed by, among others, Haegeman (1990), Hyams and Wexler (1993) and Matushansky (1995). ${ }^{8}$ Such an analysis would account for a number of restrictions on DSO.

(i) The non-overt subject is either the diary writer or a contextually salient third person referent.

(ii) DSO is disallowed in adjunct (8e) or relative clauses $(8 \mathrm{c}, \mathrm{d})$. As these domains are known to be islands for movement, the subject would have to be illicitly extracted from an island.

(iii) DSO is disallowed in complement clauses introduced by an overt C-element (8a). Extracting a subject across C-related material is independently known to lead to degradation, as shown by (33). With that deleted, (33) is grammatical:

(33) This student I don't think *( that) this student will succeed.

(iv) DSO is incompatible with argument fronting (24). To derive (24), both the object this book and the subject would have to be topicalized, with the latter non-overt. However, in English multiple argument fronting is independently known to be degraded (34).

(34) *John, this book, I will give.

(v) DSO is incompatible with root yes-no questions (22a) and wh-questions (22b). This follows from a topic drop analysis because English fronted topics are not easily compatible with yes/no questions (35a) or with fronted $w h$-items (35b): 
(35) a. *That book about shrimp, did you actually read? (cf. Sobin 2003: 194)

b. $\quad *$ ?? That book about shrimp, when did you read?

However, there remain problems for the analysis:

(i) In English subject extraction is possible with a zero complementizer (33); we incorrectly predict embedded DSO to be allowed provided there is no overt complementizer. Most speakers I consulted reject (36) and no such examples are attested:

(36) $\quad *(\mathrm{I})$ don’t think will leave.

(ii) While expletive subjects cannot be topics (31a), expletive subjects are omitted in diary writing:

(37) a. __ Rained in the night, wind, rain and hail. (Smart, Elizabeth, 1995, On the side of the angels. Flamingo/Harpers Collins. January 19, 1945, p. 27)

b. Still raining - quit about noon but remained partially cloudy all day (Carolyn's diary September 1 1964)

c. ___ _ _ Started raining this P.M...___ Poured down rain tonite - - (Carolyn's diary, August $31,1964)$

d. Cloudy \& humid all day sprinkled tonite -(Carolyn's diary, August 29, 1964)

(iii) Topic drop affects object arguments. There is no systematic object drop in the diary register. ${ }^{9}$

Section 5 presents an alternative analysis which capitalizes on the fact that DSO is restricted to a left edge constituent of the clause. ${ }^{10}$

\section{Cartography and Root Phases}

The analysis elaborated in section 5 will explore Rizzi's (2006) analysis of subject omission in early production, which shares the crucial properties of DSO (Haegeman 1997). Two crucial ingredients of analysis are the role of Phases in determining left edge ellipsis (cf. Rizzi 2006) and the cartographic approach to subjects positions (Cardinaletti 1997, 2004). I introduce these in the present section. 


\subsection{The privilege of the root: phases and spell out}

Under the movement analyses of topic drop, the specifier of the highest projection is systematically nonovert. (38) is a first representation (to be modified below) of German sentences with a non-overt topic. The topic moves to SpecCP, becoming the specifier of the root projection, $\mathrm{CP}$.

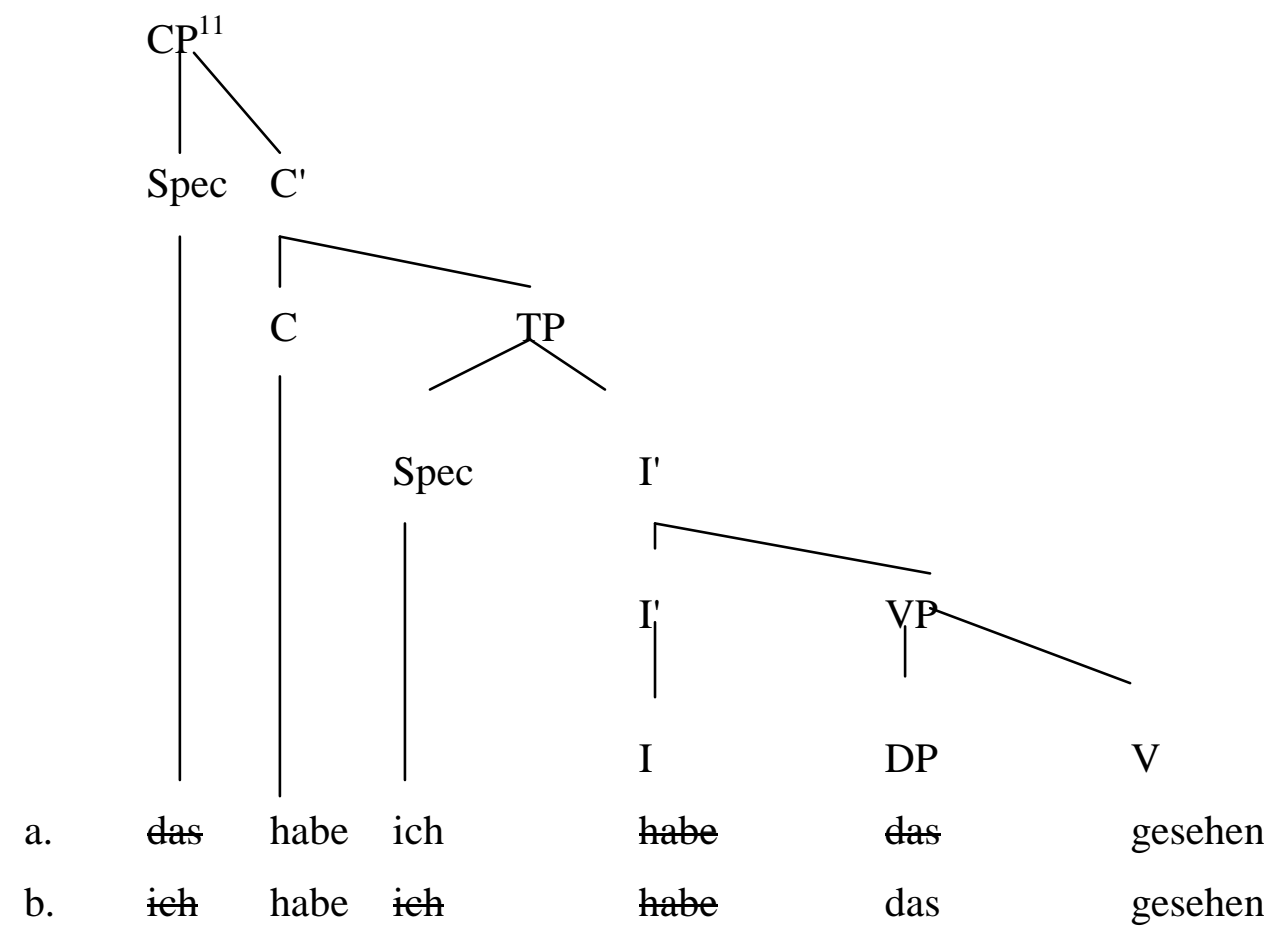

Arguments which are not in the specifier of the root cannot be non-overt $(30 \mathrm{c}, \mathrm{f})$. Rizzi $(2002,2006)$ addresses the question of why the specifier of the root is thus privileged for ellipsis. His account of subject omission in the early production assumes the phase-based approach to spell-out (Chomsky 2001, Nissenbaum 2000). Phase theory is essentially the Minimalist implementation of 'cyclicity', the hypothesis that, in the course of the computation of sentences, certain privileged domains, here called 'phases', once completed, become inaccessible for later outside influence. In particular, the propositional domain CP is considered to be a Phase. I will be adopting an intuitive notion of phase which to my mind captures the essence of the concept.

As soon as a Phase category is formed, the complement of the Phase head is sent to spell-out and no syntactic operation can operate on it any more. However, the Phase comes with an edge, the escape hatch through which elements can be extracted from a Phase and may thus survive after material in the spell out domain-i.e. the complement of the phase head - has been spelt out and has become inaccessible to later syntactic operations. The Phase-based approach to spell-out implies successive cyclicity: in order to escape being spelt out and hence frozen in place, a constituent must escape the spell out domain via the Phase edge. 
Consider (39): which text originates as the complement of the verb read in the clause embedded under think (39a) and ultimately ends up in the specifier of the $\mathrm{CP}$ of the main clause. As a first step, which text moves to the specifier of the embedded CP (39b), by assumption a Phase. Spell-out affects the TP complement of the phase head, C. Spell out is represented by italics in (39c). Crucially, the moved constituent which text in the specifier of the lower Phase escapes being spelt out, it remains syntactically active and can move to the specifier of the root $\mathrm{CP}(39 \mathrm{e})$.

(39) [Which text] do you think [the students should read]?
a. [IP the students should read which text]
b. [CР which text [TP the students should read which text]]
c. [ $\quad$ [ст which text [те the students should read which text]]]
d. [IP you think [CP which text [TP the students should read which text]
e. [СР which text do [тР you think [СР which text [тР the students should read which text]]]

Rizzi (2006) exploits an important implication of the Phase-based approach to spell-out:

The Spell-out principle also has the consequence that the edge of the Root Phase is not sent to Spell-out at all: once the root CP is formed, its complement, the [TP], is sent to spell-out ... not its edge . This has the immediate positive consequence that main clause complementizers $[=\mathrm{C}]$ (at least declarative complementizers) are normally not pronounced, while embedded complementizers may be obligatory or optional, depending on language-specific rules. (Rizzi 2006)

The Root Phase is the topmost phase in a derivation. It is the point where the derivation stops. There is, by definition, no phase that dominates the Root Phase. If the Root Phase in (39e) is CP, and if, by assumption, the edge of the Root Phase is not part of a spell out domain out, then neither the moved constituent which text in the root SpecCP or the inverted auxiliary do in the root $\mathrm{C}$ could ever be spelt out. This means that for these constituents to spell out the Root Phase must actually be a projection higher than ' $\mathrm{CP}$ ' so that CP can be in the spell out domain of a Phase. The head of the Root Phase projection will take as its complement the projection whose specifier hosts which text and whose head hosts the inverted auxiliary $d o$. In (40a) I provisionally label this Root Phase 'FP'. In this representation which text and do are in the complement of the head of the Root Phase and can be spelt out (40b).

(40) a. [FP [F $\varnothing][\mathrm{CP}$ which text do [TP you think [CP which text [TP the students should read which text]]]] 
b. $\quad\left[\mathrm{FP}[\mathrm{F} \varnothing]\left[\mathrm{CP}\right.\right.$ which text do [TP you think [ ${ }_{\mathrm{CP}}$ hich ${ }_{\mathrm{TP}}$ the students should read which text ] ] ]]

\subsection{The Split CP (Rizzi 1997) and the Root Phase}

(40) reveals the need for a more fine grained articulation of $\mathrm{CP}$, the layer which is the interface between the propositional TP domain and the (discourse) context. In independent work, Rizzi (1997) had already proposed that the $\mathrm{CP}$ be decomposed into a hierarchical sequence of specialised projections, the highest of which is ForceP, the root of the clause (41a). In root clauses, fronted interrogative constituents move to the specifier of FocP. (40b) is recast as (41b). The Root Phase CP is ForceP, with the interrogative constituent moved to FocP, and the inverted auxiliary to Foc. Hence which text and do are in the spell out domain of the Root Phase, ForceP, and can be overt.

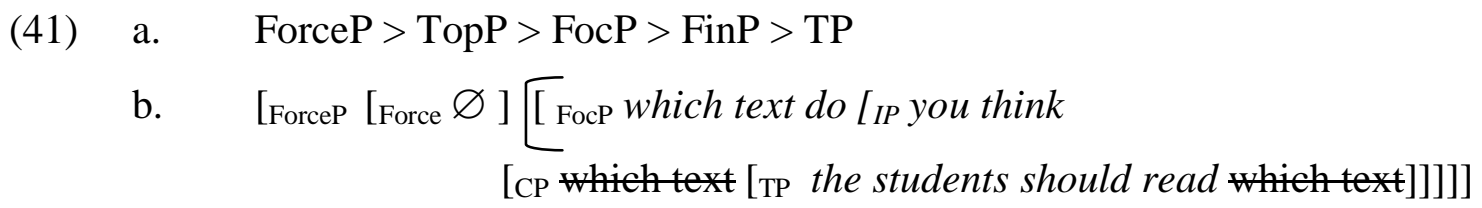

Assuming Rizzi's (1997) articulated CP, the question arises which of the projections of the CP domain can or must be a Root Phase. ForceP is a natural Root Phase in that utterances normally encode illocutionary force. But Rizzi proposes that in specific instances a lower projection may qualify as the root:

A natural approach seems to be to assume that languages may vary in a limited fashion in the inventory of the categories which count as Root Phases, i.e., the categories at which the syntactic computation can stop. ...Force presumably has the status of possible Root Phase universally, i.e. all languages have at least the option (and many have the obligation) of computing root clauses up to the Force Phrase; ... one may think of topic drop languages as languages which have the additional option of stopping the computation at the TopP, hence in which Top may count as Root Phase head, and so on. (Rizzi 2006)

If topic drop languages allow TopP as a Root Phase ${ }^{12}$, Portuguese (42a) with the null object will involve topic movement to SpecTopP. If the derivation terminates at TopP, TopP is the Root Phase and only the complement of the Phase head, Top, spells out. The specifier of the Root Phase, the fronted topic itself, remains non-overt: 


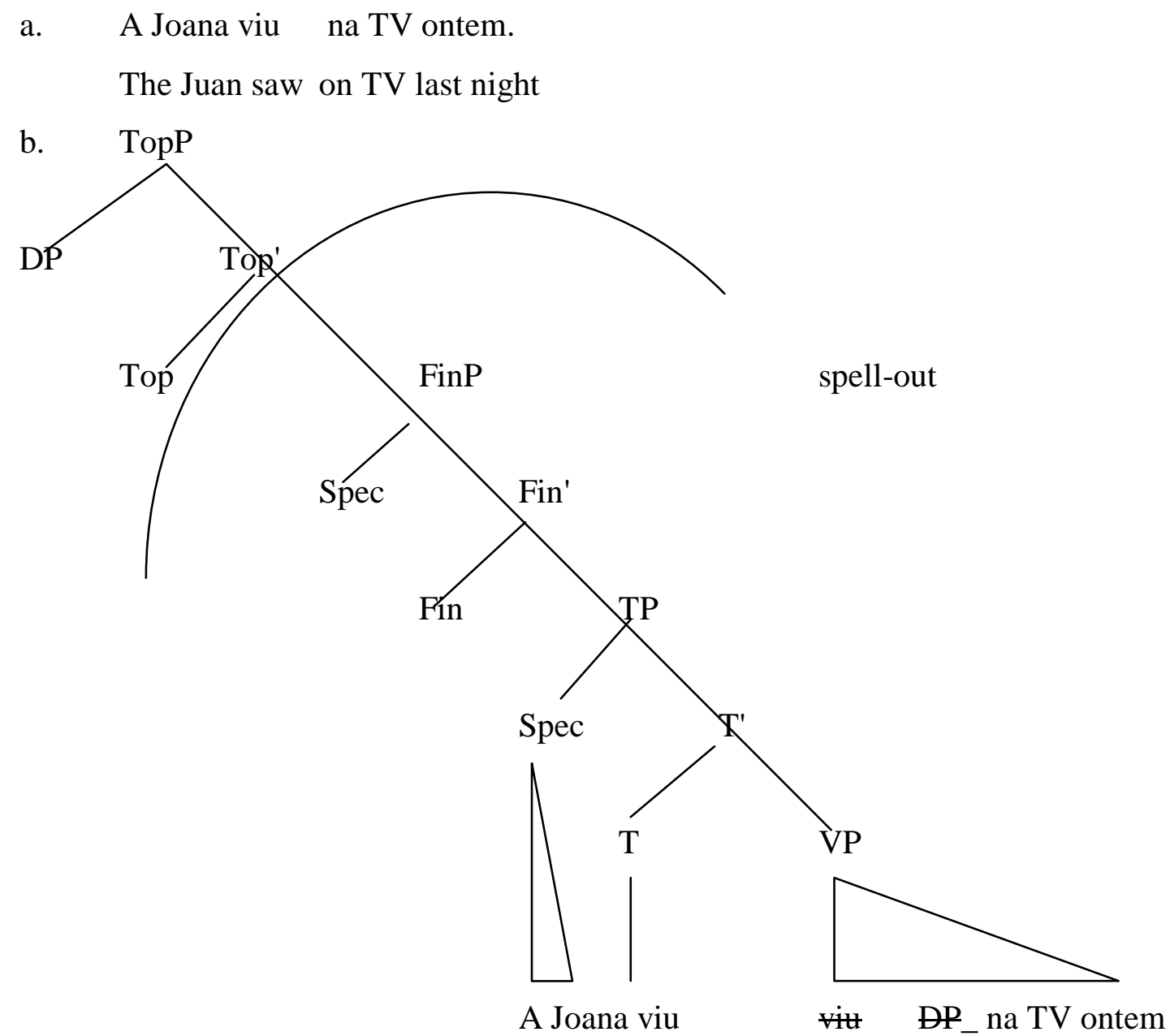

Equipped with Rizzi’s implementation of Phase-based spell-out let us return to the DSO.

\section{Diary subject drop omission}

\subsection{First hypothesis: Root Phase= TP?}

Let us assume that in the unmarked case, utterances have illocutionary Force. Put differently, in the unmarked case ForceP is the Root Phase. Spell-out affects the complement of the head Force. Hence the canonical subject position, the specifier of TP, will be in the spell out domain.

As a first hypothesis, one might assume that in DSO sentences, TP is the Root Phase.

Accordingly, the complement of $\mathrm{T}$ are spelt out whereas its specifier, the subject, and its head, $\mathrm{T}$, are not spelt out. This hypothesis allows us to derive DSO in (4), on the standard assumption (see 5.2.1. below) that the English finite verb remains in V. 
The analysis correctly predicts that examples such as (24) are not attested: when an argument is fronted the subject has to spell out and. This is so because fronted arguments move to TopP. ${ }^{13}$ In (44) the subject I occupies the specifier of of TP, i.e. it is not the specifier of the Root Phase and it is correctly predicted that it must be spelt out.

(44) [ForceP [TTopP this book [TP I didn't like $]]$

\subsection{Problems for the proposal}

\subsubsection{Finite verbs in French}

Recall French DSO in (15) with a finite lexical verb. Ever since Emonds (1978), Pollock (1989), it has been assumed that whereas the English finite verb remains in V, its French counterpart moves to T. The empirical argument for postulating this distinction is the contrast between English (45) and French (46): the English finite verb eats follows the adverb of frequency often, its French analogue mange precedes the adverb souvent:

(45) a. John often eats chocolate.

b. *John eats often chocolate.

(46) a. *Jean souvent mange du chocolat.

John often eat-3SG chocolate.

b. Jean mange souvent du chocolat.

On the assumption that TP is the Root Phase, we incorrectly predict that in a French sentence which displays DSO, the finite verb, which has moved to T, will not be able to be spelt out. For (15b) the relevant part of the derivation is illustrated in (47).

$$
\text { [те nous [т préparons] [ [vP préparens [VP les photocopies.]] }]^{14}
$$

\subsubsection{Tensed auxiliaries}

A problem similar to that displayed in the French example in (42) arises for English sentences with DSO containing tensed auxiliaries. Such examples, as we have seen $(12,13)$, were the basis for a sentential analysis. English finite auxiliaries occupy T: they precede frequency adverbs: 
c. John has always eaten chocolate.

If, in English sentences with DSO, TP were indeed the Root Phase, and if the complement of the Root head constitutes the spell out domain, (18a) would have the representation (48). Accordingly, overt finite auxiliaries should not be spelt out in sentences displaying DSO, contrary to fact.

[те I [т Have] $[$ [vр done 110 pages]]. (Diary of Virginia Woolf, V: p.33; 11 11)

The problem is the same as that raised for French in the preceding section and comes down to the fact that according to the Phase theoretic interpretation of spell out outlined here neither the head or the specifier of the Root are sent to spell-out.

To solve the problems sketched above we need to ensure that the subject occupies the specifier of the Root Phase - and thus remains outside of the spell out domain- and that $\mathrm{T}$ is not the head of the Root Phase - and hence within the spell out domain. Put differently, we need to distance the subject from T. In more technical terms: the subject and the tensed auxiliary in English, discussed in this section, and the subject and the tensed verb in French, discussed the preceding section, must not be in a local spec head configuration.

\subsubsection{The adjunct/argument asymmetry}

A further problem arises with respect to the argument -adjunct asymmetry for DSO. Recall from (26) in 3.2. that while fronted arguments are incompatible with DSO, fronted circumstantial adjuncts are available with DSO. If we assume that in (26a) the PP with a sigh of relief moves to the left periphery, and that the projection which hosts it (here labeled FP) is the complement of the Root Phase, TP will be in the spell out domain and the subject must be sent to spell out:

[ForceP [FP With a sigh of relief [TP I saw a heap of ruins]]]

\subsection{The cartography of subject positions}

It has repeatedly been proposed that the unitary subject as the specifier of TP should be reinterpreted in terms of a 'subject field' consisting of more than one functional projection and containing more than one subject position (Kiss 1996, Cardinaletti 1997, 2004, Haegeman 2002a, Rizzi 2004, 2006, Rizzi and Shlonsky 2005, Tortora and Den Dikken 2009). 


\subsubsection{English}

Consider (50) from journalistic prose: in all these examples the subject is separated from the tensed auxiliary or verb by an intervening nominal, prepositional or clausal adjunct (Haegeman 2002a):

(50) a. The critics this time can only award their prise posthumously. (Observer 30.5 .10 page 20 col 1)

b. Asked if the Prime Minister yesterday had made his position more "explicit" regarding the rebate and its negotiability, the PMOS replied: no. (www. number10. gov. uk/ output/ Page7713)

c. Cadbury in a decade's time will be a ghost of itself. (Observer 29.11.9, page 24 col 3)

d. According to you, Ed Balls, when he was schools secretary, said that he 'would not want to be in the kind of society where people were told how to dress. (Letter to the editor, Leon Bunnewell, Norwich. Observer 17.4.11 page 34 col 3)

(50) cannot be analysed as subject topicalisation, by which the subject would move to the specifier of a TopP in the left periphery. The pattern with an intervening adjunct remains available in non finite contexts (51a), and in adverbial clauses (51b,c), domains which resist argument fronting (51a', b', c') (cf. Haegeman 2002a, 2006):

(51) a. Her tale of [Ian the groom last year asking the bride's father for Chloe's hand], but swearing him to secrecy until the young lovers had left for their summer holiday was very funny. (Times, Weekend, August 19, 2000, p. 3, col. 3)

a'. *Her tale of [the bride's father Ian the groom asking for Chloe's hand]

b. I remember [when the Observer in the 60s was engaged in a fierce controversy about girls'education] ... (Observer 4.4.10 page $23 \mathrm{col} 3$ )

b'. *[When this news the Observer announced]...

c. [If the government last year had said]... (www.leg.bc.ca/hansard/37th5th/h40311p.htm )

c'. *[If this news the government had announced...]

To account for the position of the subject in (50) and (51), Haegeman (2002a), following Cardinaletti $(1997,2004)$, proposes there are two subject positions, and that the adjunct may intervene between these, hence following Subj1:

(52) Subj1 yesterday Subj2 


\subsubsection{French}

On the basis of, among others, French (53a) Rizzi and Shlonsky (2005) reinterpret the unitary subject position in terms of two positions, SpecSubjP and Spec TP, with the hierarchy in (53b):

The functional head Subj, distinct from and higher than $[\mathrm{T}]$ and other heads in the functional structure of the clause ..., attracts a nominal to its Spec and determines the subject-predicate articulation. (Rizzi and Shlonsky 2005: 4)

(53) a. Jean, la semaine prochaine, partira en Italie. (Rizzi \& Shlonsky 2005: 23: (56)) Jean the week next, leave-FUT-3SG to Italy

b. $\quad \mathrm{CP}>\mathrm{SubjP}>\mathrm{TP}$

For more discussion of the nature of SubjP, I refer to Rizzi 2004 and to Rizzi and Shlonsky (2005: 1213). I here equate my own Subj1 in (52) with their SubjP in (53b), and assume that adjuncts can intervene between SubjP and TP: ${ }^{15}$
a. SubjP
$>$ Adjunct>
$\mathrm{TP}$
b. [SubjP The Prime minister [ yesterday [TP_the prime minister had made]]
c. [SubjP Jean, [ la semaine prochaine, [тр Jean partira en Italie]].

\subsection{Diary subject omission}

Thanks to the split subject proposal outlined in section 5.3. we can effectively separate the subject from the remainder of the clause by assuming that the (non-overt) subject occupies SpecSubjP and that the head Subj remains empty. If in the diary register SubjP is the Root Phase, TP is the spell out domain: thus the constituent in $\mathrm{T}$ will be overt while the subject is non-overt. In (55) the auxiliary have in $\mathrm{T}$ is in the spell out domain, the subject $I$ in SpecSubjP is not.

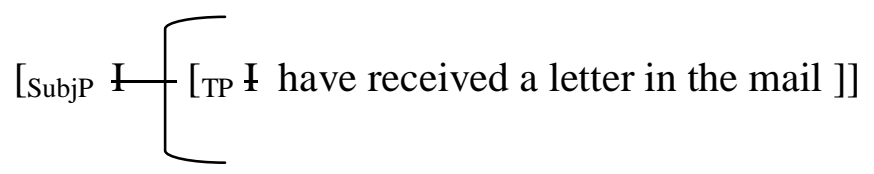

Similarly, adopting the hierarchy in (55a), the fronted adjunct is in the spell out domain, while the subject itself is in the specifier of the Root Phase and is non-overt.

$$
\text { [SubjP } \amalg[\text { [TP this morning [TP } ¥ \text { woke to get a letter in the mail]]] }
$$

We correctly predict that fronted arguments remain incompatible with DSO because argument fronting 
activates the projection TopP in the left periphery. With TopP as the root, spell-out of its complement would entail spell out of the subject (57a). With fronted interrogative constituents, one might define FocP as the Root, but this would also entail that subject is within the spell out domain (57b). Finally, embedded subjects will be trapped in a domain that is the complement of a phase head and hence will be part of a spell out domain $(57 \mathrm{c})$ :

(57) a. $\quad[$ TopP this book $[$ [SubjP I don't like $]]$
b. $[$ FocP $($ when $)$ will $[$ [SubjP I will see her $]]$
c. $\quad[$ ForceP1 I think $[$ ForceP2 that $[$ I will not see her again $]]]$

\subsection{Binding effects}

There are unexpected constraints on coreference readings for English DSO.These contrasts show that DSO does not pattern exactly like an overt pronoun. While the overt pronoun subject in (58a) may be read as coreferential with Mourinho in the fronted PP, the same reading is not available for the non overt counterpart in (58b). No such contrast emerges with respect to the genitive pronoun his in (58c,d).

(58) a. During Mourinho's $\mathrm{s}_{3}$ first year in London $\mathrm{he}_{\mathrm{n}} / 3$ became famous for his grey Armani coat.

b. During Mourinho's $s_{3}$ first year in London $[\ldots$ coat.

c. __Became Chelsea coach in 2005 and __ lived in Kensington. During his 3 first year in London he $\mathrm{n}_{\mathrm{n} / 3}$ became famous for his grey Armani coat.

d. __ _ Became Chelsea coach in 2005 and __ lived in Kensington. During his 3 first year in London, $[\ldots \ldots$ n/3] became famous for his grey Armani coat.

In DSO with an initial adjunct, my hypothesis is that the subject moves to SpecSubjP, a position higher than that of the adjunct. This is shown in (58e): the moved subject in SpecSubjP c-commands and hence illictly binds the referential Mourinho.

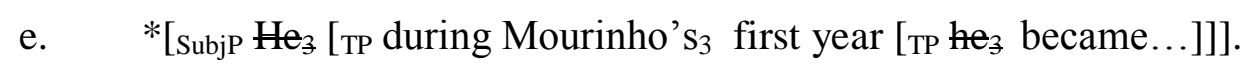

A pronominal subject to the right of the fronted adjunct (58a) does not give rise to such binding effects and can be coreferential with the DP Mourinho. 
$(58)$

f. [Subjp During Mourinho's ${ }_{3}$ first year $\left[\right.$ Subjp $_{3}$ he $_{3}\left[\mathrm{TP}_{\mathrm{T}}\right.$ he ${ }_{3}$ became... ]]].

DSO is compatible with an adjunct containing a possessive pronoun (58d): it is generally the case that possessive pronouns can be coreferential with a higher local antecedent. ${ }^{16}$

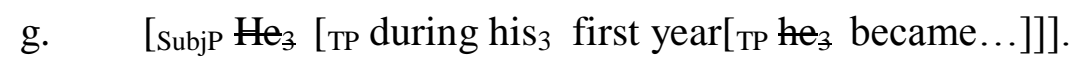

\section{Extending the analysis}

My account captures the restrictions on DSO by postulating an articulated subject field and assuming register related variability in the definition of the Root phase. The analysis accounts for both the subject/object asymmetry and the adjunct argument asymmetry of DSO. As has been discussed the distribution of non overt subjects in diary style writing is like that found in the data of early acquisition. In the present section I look at some additional areas in which subject omission is subject to the same constraints as those found to obtain in the diary style and which can thus be accounted for by the same principles.

\subsection{English abbreviated styles}

(59) contains data drawn from journalese in which information is presented in note style. (60) reproduces information on various types of sales products, in which the subject corresponds to the item on which the information is written. In both types of data, subject omission is compatible with fronted adjuncts, both in English and in French.

\section{a. Mark Webber}

Breaks a leg when hit by a car mountain-biking in Tasmania before the 2009 season. Drives with steel rods in his leg. In 2010 goes over the handlebars on a training ride and fractures shoulder one week before the Japanese grand prix. (Guardian 7.2.2011 page 3 col 1)

b. The chosen ones: Adrian Chiles v Chris Evans

\section{Volatility}

Chiles When cornered by his superiors, likes to turn up for work in a rough old beard and then sigh to himself a lot.

Evans When cornered by his superiors, __ used to like ditching work in favour of erratic day-long alcoholic benders. (Guardian G2 14.4.2010 page 11 col 2)

c. Baker's progress

In 1992 _ began writing for TV on clip show TV Hell, going on to present Win, Lose or Draw on ITV and the first series of Pets Win Prizes. (Observer 7.11 .10 page 27 col 2)

(60) a. Contains carotene (Carrot Facial Oil, The Body Shop) ${ }^{17}$ 
b. After opening, __ will keep for three days in a cool place.

\subsection{Poetic style}

Bianchi (2006) studies subject omission in Samuel Beckett'Rockaby . She reveals that the constraints I have identified for DSO also apply there. In Rockaby, the subject of 21 out of 62 finite verbs is nonovert. As is the case for the DSO, non-overt subjects are categorically restricted to root clauses; the omitted subject is either initial or it is preceded by adverbial expressions (61a). In embedded clauses the subject is always overt $(61 \mathrm{~b}, \mathrm{c}, \mathrm{d})$. The single overt subject that is found in a root clause is one that is preceded by the complement of the verb (61e), a context in which DSO would also be unacceptable. Clearly, the constraints governing subject omission in this literary text are identical to those governing DSO.

(61) a. So in the end/ Close of a long day/ Went down/ In the end went down

b. when she said to herself

c. time she stopped

d. where mother sat

e. off her head they said

\subsection{Subject omission in coordination}

Wilder (1996) was the first to draw attention to the striking parallelism between DSO and subject omission in second conjuncts (see also Maling and Sigurdsson 2007, Sigurdsson 2011):

a. I went home and wrote a few letters.

In (62a) the subject of the second conjunct is identical to that of the first conjunct, and is not overtly expressed. Subject ellipsis in second conjuncts is part of the grammar of English and is not registerspecific. However, the constraints that I identified for DSO also are found here. As is the case in DSO, the subject of a second conjunct cannot be omitted when preceded by an auxiliary (63a) or by a fronted argument $(63 \mathrm{~b}, \mathrm{c})$. Subject omission in a second conjunct is compatible with a fronted adjunct (63d):

a. *Did you go home and did _ find anything?

b. *That book, I like and this book, do not approve of. 
c. *This wine Bill has always drunk but that one has never served to anyone. (te Velde 2005: $231,(111 b))$

d. They are dedicated golf fans and for years have travelled to the Open.

Recall that DSO is restricted to matrix subjects (64a). This restriction extends to subject ellipsis in second conjuncts:

(64) a. First house was too old. v grand though.* John sure will increase over time. ${ }^{18}$

b. The first house we visited is too old. *The second house is very grand and John is sure will increase in value over time.

Though this is not the place to go into the discussion of ellipsis in second conjuncts, one way to make sense of the data presented here is to proposes that in the relevant examples the coordination affects TP and the overt subject actually in a SubjP that is common to both conjuncts. Roughly the structure of (62a) would then be as in (62b), with extraction of the subject to SubjP from both (TP) conjuncts.

b. $\quad[$ SubjP I $\quad[$ TP I went home $] \&$

[TP I wrote a few letters]]

Put differently, subject ellipsis in second conjuncts would be reinterpreted as an (across the board) extraction of the subject to a dominating SubjP. This account predicts the ungrammaticality of (64b): in the second conjunct, SubjP is here occupied by John, not by the second house. ${ }^{19}$

$$
\begin{aligned}
& \text { c. } \quad *[\text { SubjP } \text { The second house [TP the second house is very grand }]] \& \\
& \text { [TopP the secend house [SubjP John is sure } \\
& \text { [CP [Subj the secend house [TP }
\end{aligned}
$$

The prediction of this analysis is that subject ellipsis in second conjuncts will also be incompatible with focalization, which would require the projection of FocP. This prediction is confirmed. Note specifically that te Velde points out that adjunct focalization is incompatible with subject ellipsis in second conjuncts. (65) is from his discussion:

*After Boston we will pass through Providence and then FINALLY can begin the last leg to NYC. 
(te Velde 2005: 205, (49b))

Obviously, the parallelism between register-based DSO and the grammar of subject omission in second conjuncts fully warrants a grammatical account for DSO.

\section{Summary}

In this paper I have looked at register-based language internal variation, focussing on the phenomenon of subject omission in English diaries. This register-specific pattern might be seen as some kind of 'extragrammatical' stylistic convention associated with this particular register, but a survey of the relevant data shows that the omission of the subject in diary styles is subject to precise syntactic constraints. Importantly, the observed restrictions on subject omission do not follow from a purely functional account according to which recoverable subjects can be omitted: while recoverability certainly plays a role, there are precise constraints on the syntactic positions in which recoverable subjects can be omitted.

The empirical generalisation that emerges is that subjects can be omitted in root clauses. Moreover, apart from fronted adjuncts no other constituent can precede the non overt subject. The generalisation applies both to English and to French.

I have developed an account for subject omission which, in addition to standard assumptions about phrase structure, makes use of (i) the Phase based theory of ellipsis, (ii) the hypothesis of the articulated subject field. Other instantiations of subject omission such as that found in note style journalese are subject to the same restrictions. The restrictions also seem to govern subject omission in Samuel Beckett's poem Rockaby as described by Bianchi (2007), suggesting that indeed the pattern is subject to grammatical constraints which are not exclusively tied to the specific register. Finally, subject ellipsis in second conjuncts, a phenomenon which does not have a register-specific distribution, is subject to the same restrictions as subject omission in the diary style and can be accounted for using the hypotheses developed here. The conclusion I draw from this discussion is that the grammatical patterns displayed by what might seem a culturally determined linguistic system are fully amenable to core principles and parameters of universal grammar.

\section{References}

Alexiadou, A., L. Haegeman and M. Stavrou. 2008. Noun phrase from the generative perspective. Berlin: Mouton-De Gruyter.

Barton, E.L. 1998. The grammar of telegraphic structures. Journal of English Linguistics 26, 37-67. 
Bianchi, V. 2006. Subjectless language: Syntactic aspects of S. Beckett's 'Rockaby'. Rivista di Grammatica Generativa 31.

Biber, D. 1995. Dimensions of Register Variation: A Cross-linguistic Comparison. Cambridge: Cambridge University Press.

Bromberg, H. \& K. Wexler. 1995. Null Subjects in wh-questions. In: C. T. J. B. Schütze, C. Ganger \& K. Broihier (eds), Papers on Language Processing and Acquisition, MIT Working Papers in Linguistics 26, 221-248.

Cardinaletti, A. 1997. Subjects and clause structure. In: L. Haegeman (ed.), The New Comparative Syntax. London: Longman. 33-63.

Cardinaletti, A. 2004. Toward a cartography of subject positions. In: L. Rizzi (ed.), The Structure of CP and IP. Oxford and New York: Oxford University Press. 115-165.

Chomsky, N. 2001. Derivation by phase. In: M. Kenstowicz (ed.), Ken Hale: A Life in Language, MIT Press, Cambridge, Mass.

Cinque, G. and L. Rizzi. 2010. The cartography of syntactic structures. The Oxford handbook of grammatical analysis, ed. Bernd Heine and Heiko Narrog. 51-65. Oxford University Press. Emonds, Joseph. 1978. The Verbal Complex V' - V in French. Linguistic Inquiry 9: 151-175.

Ferguson, C.A. 1982. Simplified registers and linguistic theory. In: L. K. Obler \& L. Menn (eds), Exceptional Language and Linguistics. New York: Academic Press. 49-66.

Haegeman, L. 1987. Register variation in English: Some theoretical observations. Journal of English Linguistics 20, 230-248.

Haegeman, L. 1990. Non-overt subjects in diary contexts. In: J. Mascaro \& M. Nespor (eds), Grammar in Progress, GLOW essays for Henk van Riemsdijk. Dordrecht: Foris. 167-174.

Haegeman, L. 1997. Register variation, truncation and subject omission in English and in French. English Language and Linguistics 1, 233-270.

Haegeman, L. 1999. Adult null subjects in non pro-drop languages. In: M.-A. Friedemann \& L. Rizzi (eds.) The Acquisition of Syntax. Addison, Wesley and Longman, London.

Haegeman, L. 2002a. Sentence-medial NP-adjuncts in English. Nordic Journal of Linguistics 25, 79-108. Haegeman, L. 2002b. Non-overt subject pronouns in written English. In: S. Scholz, M. Klages, E.

Hantson \& U. Römer (eds), Language, Context and Cognition. Papers in Honour of Wolf Dietrich Bald's 60th Birthday. Munchen: Langenscheidt, Longman. 135-149

Haegeman, L. 2006. Argument fronting in English, Romance CLLD, and the left periphery. In: R. Zanuttini, H. Campos, E. Herburger \& P. Portner (eds), Crosslinguistic Research in Syntax and Semantics. Negation, Tense and Clausal Architecture. Washington D.C.: Georgetown University Press. 27-52. 
Haegeman, L \& T. Ihsane 1999. Subject ellipsis in embedded clauses in English. Journal of English Language and Linguistics 3, 117-45.

Haegeman, L. \& T. Ihsane. 2002. Adult null subjects in the non-pro-drop languages: two diary dialects. Language Acquisition 9, 329-346.

Hamann, C., L. Rizzi \& U. Frauenfelder. 1996. On the acquisition of subject and object clitics in French. In: H. Clahsen (ed.), Generative Perspectives on Language Acquisition. Amsterdam/ Philadelphia: John Benjamins. 309-334.

Hattori, Shiro. 1960. Gengogaku to hoohoo (Linguistics and methodology). Tokyo: Iwanami. Horsey, R. 1998. Null Arguments in English Registers. A Minimalist Account, BA thesis, La Trobe University, Australia.

Huang, J. 1984. On the distribution and reference of empty pronouns. Linguistic Inquiry 15, 531-574. Hyams, N. 1986. Language Acquisition and the Theory of Parameters. Reidel, Dordrecht. Hyams, N. \& K. Wexler. 1993. On the grammatical basis of null subjects in child language. Linguistic Inquiry 24, 412-459.

Ihsane, T. 1998.. The syntax of diaries: grammar and register variation. Uni. of Geneva. Ms Jaeggli, O. and K. Safir. 1989. The Null subject parameter. Dordrecht: Kluwer.

Janda, R. J. 1985. Note-taking English as a simplified register. Discourse Processes 8, 437-454.

Kiss, K. 1996. Two subject positions in English. Linguistic Review 13, 119-142.

Massam, D. 1989. Null objects and non-thematic subjects. Journal of Linguistics 28, 115-137.

Massam, D. \& Roberge, Y. 1989. Recipe context null subjects. Linguistic Inquiry 20, 134-139.

Matushansky, O. 1995. Le sujet nul dans les propositions à temps fini en anglais. Maîtrise paper, Paris VIII.

Napoli, D. 1982. Initial material deletion in English. Glossa 16 : 85-111.

Nasu, N. 2010. The distribution of particles in Japanese and the structure of CP. Paper presented at GIST2 : Main Clause Phenomena. Ghent University, 29.9.2010.

Newmeyer, F. 2003. Grammar is grammar and usage is usage. Language 79, 682-707.

Nissenbaum, J. 2000. Investigations of covert phrasal movement, PhD Dissertation, MIT, Cambridge, MA.

Platzack, C. 1998. A Visibility Condition for the C-domain. Working Papers in Scandinavian Syntax 61, 53-99.

Pollock, J.-Y. 1989. Verb movement, UG and the structure of IP. Linguistic Inquiry 20, 365-425.

Progovac L., K. Paesani, E. Casielles \& E. Barton. 2006. The Syntax of Non-sententials. Amsterdam/Philadelphia: John Benjamins.

Raposo, E. 1986. The null object in European Portuguese. In: O. Jaeggli \& C. Silva-Corvalàn (eds.), 
Studies in Romance Linguistics. Dordrecht: Foris. 373-390.

Rizzi, L. 1982. Issues in Italian Syntax. Dordrecht: Foris.

Rizzi, L. 1994. Early null subjects and root null subjects. In: Hoekstra, T. \& B. Schwartz. (eds.),

Language Acquisition Studies in Generative Grammar. Amsterdam/Philadelphia: John Benjamins. 151-177.

Rizzi, L. 1995. Some notes on linguistic theory and language development: the case of root infinitive. Language Acquisition 3, 371-393.

Rizzi , L. 1997. The fine structure of the left periphery. In: L. Haegeman (ed.), Elements of Grammar. Kluwer: Dordrecht.

Rizzi, L. 1999. Remarks on early null subjects. In: M.-A. Friedemann and L. Rizzi (eds), The Acquisition of Syntax. London: Longman. 269-292.

Rizzi, L. 2001. Relativized minimality. In: M. Baltin \& C. Collins (eds), The Handbook of Contemporary Syntactic Theory. Oxford and Boston: Blackwell. 89-110.

Rizzi, L. 2002. On the grammatical basis of language development. A Case Study.' Ms. University of Siena.

Rizzi, L. 2004. On the form of chains: criterial positions and ECP effects. Ms. University of Siena.

Rizzi, L. 2006. Grammatically-based target-inconsistencies in child language. In: Deen, K.U., J. Nomura, B. Schulz \& B.D. Schwartz (eds), The Proceedings of the Inaugural Conference on Generative Approaches to Language Acquisition -North America (GALANA). UCONN / MIT Working Papers in Linguistics. Cambridge, MA: MIT Press, 2006.

Rizzi, L. 2007. On some properties of criterial freezing, CISCL. Studies in Linguistics. 1, 145-15

Rizzi, L. \& U. Shlonsky. 2005. Strategies of subject extraction. In: Gärtner, H-M. \& U. Sauerland, (eds.). Interfaces + Recursion = Language?, Berlin: Mouton de Gruyter, 115-160.

Rizzi, L. \& U. Shlonsky. 2006. Satisfying the Subject Criterion by a non-subject: English locative inversion and heavy NP shift. In: Frascarelli, M. (ed.), Phases of interpretation, Berlin: Mouton de Gruyter, 341-361.

Tortora, C. \& M. den Dikken. 2010. Subject agreement variation: support for the configurational approach. Lingua 120, 1089-1108.

Sato, Y. 2001. Particle-standing Ellipsis in Japanese, Phase theory and the Privilege of the Root. Ms. Department of English Language and Literature. U. Singapore.

Schmerling, S. 1973. Subjectless sentences and the notion of surface structure. In: C. Corum, T. C. Smith \& A. Weiser (eds), Papers from the Ninth Regional Meeting of the Chicago Linguistic Society. $577-586$.

Sigurđsson H.A. \& J. Maling. 2007. Argument drop and the Empty Left Edge Condition (ELEC). Ms. 
Lund University-Brandeis University.

Sobin, N. 2003. Negative inversion as nonmovement. Syntax 6: 183-222.

Stowell, T. 1996. Empty heads in abbreviated English. Ms. UCLA .

Thrasher, R. 1977. One Way to Say More by Saying Less. A Study of so-called Subjectless Sentences.

Kwansei Gakuin University Monograph Series Vol. 11, The Eihosha Ltd, Tokyo.

Velde, J. te. 2005. Deriving Coordinate Symmetries. Amsterdam/Philadelphia: John Benjamins.

Weir, A. 2009. Subject pronoun drop in informal English. Richard M. Hogg Prize winning essay.

http://people.umass.edu/aweir/

Wilder, C. 1994. Some properties of ellipsis in coordination. Geneva Generative Papers 2, 2, 23-61. Also in: A. Alexiadou \& T.A. Hall (eds.) (1997) Studies in Universal Grammar and Typological Variation. Amsterdam/Philadelphia: John Benjamins. 59-107.

Zwicky, A.M. \& A.D. Zwicky. 1982. Register as a dimension of linguistic variation. In: R. Kittredge \& J. Lehrberger (eds), Sublanguage. 213-8

Reference: online diaries

Carolyn's diary. The daily life of an American woman. Online

Orwell diaries

http://www.google.be/search?hl=nl\&source=hp\&q=orwell+diaries\&aq=f\&aqi=\&aql=\&oq=Orwell 's domestic and political diaries (from 9th August 1938 until October 1942) published as a blog, exactly 70 years after the respective original entry.

orwelldiaries.wordpress.com/

President Harry S.Truman's 1947 Diary Book, 1947 Diary and Manual of the Real Estate Board of New

York, Inc. Transcribed by Raymond H. Geselbracht, Education and Academic Coordinator-

http://www.trumanlibrary.org/diary/index.htmlHarry S. Truman 1947 Diary.

Letters and Diaries of Narcissa Whitman. Oregon trail. March December 1836

http://www.isu.edu/ trinmich/00.ar.whitman1.html.

Reference: published diaries

Léautaud, P. Le Fléau, Journal particulier. 1917-1930, pp. 69-70, 20.3)

Smart, E. (1991). Necessary secrets. Ed. A. van Wart. London and Edinburgh: Paladin (Harper Collins). 163-182.

Plath, S. (1982) .The journals of Sylvia Plath. Eds. T. Hughes and F. McCollough. New York: Ballantine (Random House). 284-303. 
Woolf, V. (1982) The diary of Virginia Woolf, Volume 3: 1925-1930. Eds. A. Olivier Bell assisted by A. McNeillie. Middlesex: Penguin Books. First published by Chatto and Windus: The Hogarth Press. (1980).

Woolf, V. (1985) The diary of Virginia Woolf, Volume 5: 1936-1941. Eds. A. Olivier Bell assisted by A. McNeillie. Middlesex: Penguin Books. First published by Chatto and Windus: The Hogarth Press. (1984).

This research is funded by - FWO 2009-Odysseus-Haegeman-G091409.

Following current practice I label nominal expressions 'DP' for Determiner Phrase, the assumption being that the head of the projection is the determiner D. For discussion see Alexiadou, Haegeman and Stavrou 2008.

See Hyams (1986) for a pro-drop analysis of early null subjects such as those in (9).

For spoken English this restriction was observed by Napoli (1982), Schmerling (1973: 583) and by Thrasher (1977: 29).

Telegraphic style allows subject omission in embedded clauses:

(i) Regret cannot attend. (Barton 1998:54)

What did was take 'sha' and... (Janda 1985: 445)

For diary styles with embedded null subjects see Haegeman and Ihsane $(1999,2002)$.

cf. (i) This book: didn't like it.

In this example the fronted argument and the clause each have their own intonation contour, and there is a clear pause between the two, suggesting the two entities are syntactically separate. Thanks to the members of the Cambridge Linguistic Society and esp. to Prof. Peter Matthews for helpful discussion of such examples.

Thanks to Danièle Vandevelde and Damien Laflaquière for judgements.

Observe: implicit topics are not available in all V2 languages. West Flemish does not have implicit topics.

A topic drop analysis of subject omission in early grammars was proposed by Hyams and Wexler (1993), Bromberg and Wexler, (1995: 243-4) among others.

Instructional writing (recipes) allows object drop, as shown in (5).

For an earlier analysis that was very much focussed on the left edge nature of ellipsis see Rizzi $(1994,1995,1999)$ for the early production data and Haegeman $(1997,1999)$ for the DSO. Horsey $(1998)$ is a minimalist reinterpretation of Haegeman's account of RRSO, see also Sigurdsson and Maling (2007).

This diagram assumes that $\mathrm{V} 2$ is derived by head movement and it does not take into account the problem of deriving OV orders.

It is not clear what determines the possibility for TopP to be a Root Phase. Crucially, the V2 property cannot be the decisive factor since West Flemish is a V2 language and does not have 'German style' topic drop. TopP cannot be a Root Phase in English.

For clarity of presentation, I omit irrelevant parts of the structure such as the VP internal copy of the subject.

Rizzi (2001) assumes adjuncts land in a dedicated projection 'ModP'. For ease of exposition, I will not represent this projection in the representations above and assume adjuncts are adjoined to maximal projections (i.c., TP).

A complication for this issue is that in Italian too a nominal in a preposed adjunct cannot be coreferential with a null subject, though it can corefer with an overt pronoun. For reasons of space I do not go into this here. 
17 Observe that the same pattern is found for French, where (ib) illustrates a fronted adjunct in the context of subject omission:

(i) a. $\quad$ Stimule le corps et l'esprit. ..

Stimulate-3SG the body and the mind

b _ Après chaque oblitération ___ _ donne droit à la libre circulation pendant 60 min. after each checking entitles to free circulation during $60 \mathrm{~min}$.

(Geneva public transport card, 1998, 'Carte multiparcours')

Thanks to David Adger (p.c.) for the example. Thanks to David Adger and Rachel Nye for the judgements.

19 The subject in the first conjunct cannot move to TopP. This is in line with Rizzi (2004, 2006) and Rizzi \& Shlonsky (2005) who assume that the constituent in SpecSubjP cannot move to a higher position. 